\title{
Standardised Registration of Surgical Complications in Laparoscopic-Gynaecological Therapeutic Procedures Using the Clavien-Dindo Classification
}

\author{
Standardisierte Erhebung chirurgischer Komplikationen bei laparoskopisch-gynäkologischen \\ Therapieverfahren unter Anwendung der Clavien-Dindo-Klassifikation
}

Authors

Affiliations
M. P. Radosa ${ }^{1}$, G. Meyberg-Solomayer ${ }^{2}$, J. Radosa ${ }^{2}$, J. Vorwergk ${ }^{1}$, K. Oettler ${ }^{1}$, A. Mothes ${ }^{1}$, S. Baum² , I. Juhasz-Boess ${ }^{2}$, E. Petri ${ }^{3}$, E. F. Solomayer ${ }^{2}$, I. B. Runnebaum

${ }^{1}$ Department of Gynecology and Obstetrics, Jena University Hospital, Jena

2 Department of Obstetrics and Gynecology, University of Saarland, Homburg/Saar

${ }^{3}$ Department of Obstetrics and Gynecology, University Greifswald, Greifswald

\begin{abstract}
Key words
- laparoscopy

- gynaecological surgery

complications

Schlüsselwörter

- Laparoskopie

- gynäkologische Chirurgie

- Komplikationen
\end{abstract}

Deutschsprachige

Zusatzinformationen online abrufbar unter: www.thieme-connect.de/ ejournals/toc/gebfra $\begin{array}{ll}\text { received } & 7.4 .2014 \\ \text { revised } & 18.6 .2014 \\ \text { accepted } & 30.6 .2014\end{array}$

Bibliography

Dol http://dx.doi.org/

10.1055/s-0034-1382925

Geburtsh Frauenheilk 2014; 74 :

752-758 @ Georg Thieme

Verlag KG Stuttgart - New York . ISSN 0016-5751

\section{Correspondence}

Prof. Ingo B. Runnebaum

Jena University Hospital

Department of Gynecology

and Obstetrics

Bachstraße 18

07743 Jena

direktion-gyn@med.uni-jena.de

\section{Abstract}

$\nabla$

Introduction: The registration of complications represents an important component in the evaluation of surgical therapeutic procedures. The aim of the present study was to examine the frequency of occurrence as well as the severity of surgical complications after laparoscopic-gynaecological operations in a standardised manner using the Clavien-Dindo system.

Material and Methods: Altogether 7438 treatment courses after laparoscopic-gynaecological interventions by 9 working groups were evaluated. Covariates recorded were the technical complexity of the operation, type of study cohort, study size, data acquisition as well as study centre. Target variables recorded were the surgical morbidity rate, subdivided into mild (ClavienDindo grade I-II) and severe complications (Clavien-Dindo grade III-V). In addition, a binary logistic regression analysis for the mentioned covariates and the occurrence of surgical complication was carried out.

Results: 946 complications were recorded (overall complication rate: $13 \%)$. These included 664 mild complications (8.9\%) and 305 severe complications (4.1\%). A correlation was found between the covariates technical complexity (relative risk [rR] 1.37; $\mathrm{p}<0.01$ ), study size (rR: $0.35 ; \mathrm{p}<0.01$ ) and study centre (rR 0.19; $\mathrm{p}<0.01$ ) and the occurrence of surgical complications.

Conclusion: By means of a standardised registration of complications using the Clavien-Dindo classification it appears to be possible to limit the methodologically caused underestimation of surgical morbidity in the retrospective evaluation of gynaecological-endoscopic therapeutic procedures. Factors decisively influencing the surgical morbidity of gynaecological-laparoscopic therapeutic procedures are the respective operative experience of the treating facility as well as the technical complexity of the intervention.

\section{Zusammenfassung \\ $\nabla$}

Einführung: Die Erfassung von Komplikationen stellt einen wichtigen Bestandteil bei der Evaluation operativer Therapieverfahren dar. Ziel der vorliegenden Arbeit war es, die Häufigkeit des Auftretens sowie die Schwere von chirurgischen Komplikationen nach laparoskopisch-gynäkologischen Operationen standardisiert mithilfe des Clavien-Dindo-Systems zu untersuchen.

Material und Methodik: Insgesamt 7438 Behandlungsverläufe nach laparoskopisch-gynäkologischen Eingriffen, erhoben von 9 Arbeitsgruppen, wurden ausgewertet. Als Kovariaten wurden technischer Schwierigkeitsgrad des Eingriffs, Art der Studienkohorte, Studiengröße, Datenakquise sowie Studienzentrum erfasst. Als Zielvariable wurde die chirurgische Morbiditätsrate, unterteilt in leichte (Clavien-Dindo Grad I-II) und schwere Komplikationen (Clavien-Dindo Grad III-V) erhoben. Ferner erfolgte eine binär logistische Regressionsanalyse für die aufgeführten Kovariaten und dem Auftreten von chirurgischen Komplikationen.

Resultate: 946 Komplikationen wurden erfasst (Gesamtkomplikationsrate: 13\%). Hierbei handelte es sich um 664 leichte Komplikationen (8,9\%) und 305 schwere Komplikationen (4,1\%). Es zeigte sich eine Korrelation zwischen den Kovariaten technischer Schwierigkeitsgrad (relatives Risiko [rR] 1,37; $\mathrm{p}<0,01$ ), Studiengröße (rR: 0,35; $\mathrm{p}<0,01$ ) und Studienzentrum ( $\mathrm{rR} \mathrm{0,19;} \mathrm{p}<0,01$ ) und dem Auftreten chirurgischer Komplikationen.

Schlussfolgerungen: Durch eine standardisierte Komplikationserfassung mithilfe der Clavien-Dindo-Klassifikation erscheint es möglich, die methodisch bedingte Unterschätzung der chirurgischen Morbidität bei der retrospektiven Auswertung von gynäkologisch-endoskopischen Therapieverfahren zu begrenzen. Als die chirurgische Morbidität gynäkologisch-laparoskopischer The- 
rapieverfahren maßgeblich beeinflussende Faktoren wurden die jeweilige operative Erfahrung der durchführenden Behandlungseinrichtung sowie der technische Schwierigkeitsgrad des Eingriffs identifiziert.

\section{Introduction}

\section{$\nabla$}

The registration of postoperative complications represents an essential component in the evaluation of surgical treatment procedures [1]. Currently the registration of surgical morbidity in clinical case series is, however, difficult due to the lack of a widely accepted definition of the term "complication" [2]. Standardised classification systems for recording the surgical morbidity of surgical interventions provide uniform definitions for the existence of a complication as well as for its degree of severity. They are thus helpful in the recording of the surgical morbidity of a surgical technique, in the categorisation of the severity of the observed event and thus improve the comparability of individual studies on surgical procedures [3]. In the daily clinical routine, standardised systems for recording complications contribute to a structured quality assurance in gynaecological endoscopy and thus to a higher quality of care $[4,5]$. The Clavien-Dindo classification is one such standardised system for the registration of surgical complications. It defines the occurrence of a complication as any deviation from the ideal postoperative course that is not inherent to the operation and that cannot be considered as a therapeutic failure of the operation. In concept, the classification is made according to the degree of severity on the basis of the respective therapeutic intervention that led to treatment of the observed deviation ( Table 1) [6]. In its current revised form, the Clavien-Dindo classification has experienced an exponential use in visceral and urological clinical research in the course of the past two decades; its use to record surgical complications in the course of scientific evaluations is recommended in the two specialties $[7,8]$. In contrast, the use of standardised systems to

Table 1 Classification for recording postoperative complications in its revised version according to Clavien and Dindo [6].

\begin{tabular}{|c|c|}
\hline Degree & Definition \\
\hline I & $\begin{array}{l}\text { Every deviation from normal postoperative course without the } \\
\text { necessity for drug treatment or a surgical, endoscopic or radio- } \\
\text { logical intervention. } \\
\text { Permissible therapeutic measures: drugs from the substance } \\
\text { classes antiemetics, antipyretics, analgesics, diuretics; electro- } \\
\text { lyte substitution and physiotherapy. Surgical treatment of } \\
\text { wound infections at the bedside. }\end{array}$ \\
\hline II & $\begin{array}{l}\text { Drug treatment in excess of the pharmacological measures } \\
\text { listed under degree I. Blood transfusions and parenteral nutri- } \\
\text { tion. }\end{array}$ \\
\hline III & Necessity for surgical, endoscopic or radiological intervention. \\
\hline III a & Intervention without general anaesthesia. \\
\hline IIIb & Intervention with general anaesthesia. \\
\hline IV & $\begin{array}{l}\text { Life-threatening complications leading to transfer to an inter- } \\
\text { mediate care or intensive care unit. }\end{array}$ \\
\hline IVa & $\begin{array}{l}\text { Dysfunction of an organ system (including the necessity for } \\
\text { temporary dialysis). }\end{array}$ \\
\hline IV b & Multiorgan dysfunction. \\
\hline V & Death of the patient. \\
\hline Suffix d & $\begin{array}{l}\text { The complication degree is given the suffix "d" if the complica- } \\
\text { tion needs further treatment after release of the patient from } \\
\text { hospital. }\end{array}$ \\
\hline
\end{tabular}

register surgical complications in general and the use of the Clavien-Dindo classification in particular has yet not found regular usage in the published gynaecological research literature. The current evaluation of our own laparoscopic-gynaecological therapeutic interventions as well as those of treatment courses from other institutions identified in a selective search of the literature in which the occurrence and degree of severity of surgical complications were primarily recorded with the help of the ClavienDindo classification was carried out with the objective to examine the frequency of occurrence as well as the degree of severity of surgical complications after endoscopic gynaecological procedures by means of a standardised registration method.

\section{Materials and Methods \\ $\nabla$}

\section{Study design}

In the present analysis we included 1050 laparoscopic-gynaecological treatment courses from our own groups that were evaluated in a standardised manner using the Clavien-Dindo classification as well as 6388 published treatment course from other working groups.

The Clavien-Dindo classification as a tool for the standardised registration of surgical morbidity has been in use in the framework of clinical research projects in our working group at the Department of Gynaecology and Obstetrics, Jena University Hospital since 2009 and since 2011 at the Department of Gynaecology and Obstetrics, University Hospital of the Saarland. For the present analysis all standardised treatment courses after laparoscopic interventions that were recorded in the course of scientific clinical evaluations by our group in both treatment centres up to July 2013 were collected in anonymised form in a complication register by means of an electronic data base (SPSS Statistics, Version 22, IBM, Armonk, USA).

For the identification of previously published treatment courses evaluated by means of the Clavien-Dindo classification after laparoscopic-gynaecological interventions, we performed a literature search in July 2013 with the help of the databank ISI Web of Science. All original papers and meta-analyses from the field of gynaecology which contained references to the Clavien-Dindo classification among the citations were selected $[6,9] .57$ publications were primarily identified and, in a subsequent step, subjected to abstract text analysis in order to select articles concerning laparoscopic-gynaecological treatment procedures. Ten contributions published by nine working groups were finally chosen ( Table 2) [10-19] and the described treatment courses were entered into our complication register for further analysis.

\section{Methods of evaluation}

For the included treatment courses consisting of study cohorts from our own group as well as study cohorts identified by means of a literature search the covariates degree of technical difficulty of the laparoscopic intervention, study size, data acquisition as well as study centre were recorded. For those treatment courses identified by means of the literature search, registration of these covariates was achieved by a full text analysis of the respective pub- 
Table 2 Selected publications.

\begin{tabular}{|c|c|c|c|c|c|c|}
\hline Study & $\begin{array}{l}\text { Publication } \\
\text { type }\end{array}$ & Therapeutic procedures & $\mathbf{n}$ & $\begin{array}{l}\text { Degree of } \\
\text { difficulty }\end{array}$ & Study cohort & $\begin{array}{l}\text { Data } \\
\text { acquisition }\end{array}$ \\
\hline Chi D et al., 2004 [10] & original paper & various surgical procedures & 1451 & I/II/III/IV & oncological & prospective \\
\hline Siedhoff MT et al., 2012 [11] & original paper & hysterectomy & 834 & II & mixed & retrospective \\
\hline Alperin M et al., 2012 [12] & original paper & hysterectomy & 446 & II & mixed & retrospective \\
\hline Fagotti A et al., 2012 [13] & original paper & $\begin{array}{l}\text { radical hysterectomy with retro- } \\
\text { peritoneal lymphadenectomy }\end{array}$ & 75 & IV & oncological & retrospective \\
\hline Soudaka A et al., 2012 [14] & original paper & retroperitoneal lymphadenectomy & 98 & IV & oncological & retrospective \\
\hline Palomba S et al., 2012 [15] & original paper & retroperitoneal lymphadenectomy & 403 & IV & oncological & retrospective \\
\hline Kondo W et al., 2011 [16] & original paper & hysterectomy & 2092 & II & mixed & retrospective \\
\hline Kondo W et al., 2011 [17] & original paper & $\begin{array}{l}\text { resection of deeply infiltrating } \\
\text { endometriosis }\end{array}$ & 568 & IV & mixed & retrospective \\
\hline Gendy R et al., 2011 [18] & meta-analysis & hysterectomy & 332 & II & mixed & prospective \\
\hline Hong JH et al., 2010 [19] & original paper & retroperitoneal lymphadenectomy & 89 & IV & oncological & retrospective \\
\hline
\end{tabular}

Study: included publications; Therapeutic procedures: investigated laparoscopic therapeutic procedure; n: number of included treatment courses; Degree of difficulty: technical degree of difficulty of the analysed therapeutic procedure according to Barakat (Chi et al., 2004); Study cohort: type of investigated study collective; Data acquisition: type of data acquisition.

lication. For an assignment according to degree of technical difficulty of the respective laparoscopic procedure, we used the classification suggestion by the group of Barakat and Abu-Rustum into interventions with low or medium degrees of technical difficulty (Levels I-II) and those with enhanced or higher degrees of difficulty (Levels III-IV) ( Table 3) [10]. For the type of study cohort we distinguished between mixed study cohorts and study cohorts in which exclusively the treatment courses of gynaecological-oncological patients were assessed. For the covariate study size treatment courses from research projects with patient cohorts containing less than 500 patients and analyses with cohorts of 500 or more patients were compared. For the covariate data acquisition a distinction was made as to whether the postoperative complications arising in the included treatment courses were recorded retrospectively or prospectively. With regard to the covariate study centre, a comparison was made between treatment courses evaluated by our own group and the treatment courses from other working groups. For the included treatment courses the postoperative complications recorded as target variables by means of the Clavien-Dindo classification

Table 3 Classification laparoscopic interventions according to degree of technical severity after Chi et al. [10].

\begin{tabular}{|c|c|}
\hline $\begin{array}{l}\text { Degree of } \\
\text { difficulty }\end{array}$ & Type of intervention \\
\hline Stage I & diagnostic laparoscopy \\
\hline Stage II & $\begin{array}{l}\text { uni- or bilateral adnexectomy } \\
\text { - uni- or bilateral cyst ablation on the ovary } \\
\text { hysterectomy (laparoscopic, supracervical, } \\
\text { laparoscopy-assisted vaginal) } \\
\text { myomectomy } \\
\text { adhesiolysis/resection of superficial endometriosis lesion }\end{array}$ \\
\hline Stage III & $\begin{array}{l}\text { second-look laparoscopy after laparotomy in } \\
\text { gynaecological-oncological patients } \\
\text { reconstructive uro-gynaecological surgery } \\
\text { adhesiolysis after oncological, surgical interventions } \\
\text { in abdomen or pelvis }\end{array}$ \\
\hline Stage IV & $\begin{array}{l}\text { retroperitoneal lymphadenectomy } \\
\text { extended hysterectomy } \\
\text { resections of intestine/bladder/ureter with or without } \\
\text { laparoscopic suture or, respectively, anastomosis }\end{array}$ \\
\hline
\end{tabular}

were subdivided into mild (Clavien-Dindo grade I-II) and severe complications (grade III-V). Complications of severity degree $\mathrm{V}$ according to Clavien-Dindo were used for calculation of the mortality rate in the evaluated treatment courses.

\section{Statistics}

After a descriptive analysis of the data, further investigations with regard to a relationship between the above-mentioned covariates and the occurrence of postoperative complications were undertaken. For this we performed a binary logistic regression analysis for the covariates degree of technical difficulty, cohort size, data acquisition, study cohort and study centre and the occurrence of postoperative complications overall, the occurrence of mild postoperative complications and the occurrence of severe postoperative complications. For each covariate we also calculated the Wald statistics, the relative risk, the significance level p, and the $95 \%$ confidence interval.

\section{Results}

Descriptive analysis

Altogether 7438 treatment courses were included in the analysis. Of these 1050 treatment courses from our own working groups within the framework of four clinical evaluations on laparoscopic-gynaecological treatment procedures were assessed. At the Department of Gynaecology and Obstetrics, Jena University Hospital the surgical morbidity of 553 interventions was recorded retrospectively, of these 451 interventions were of degree of techninal difficulty II and 102 interventions were of technical difficulty degree III [20,21]. 497 treatment courses from the Department of Gynaecology and Obstetrics at the University of the Saarland were evaluated, of these 202 treatment courses were of difficulty degree II in the framework of a retrospective evaluation on quality of life after laparoscopic hysterectomy and 295 were of difficulty degree II in a prospective clinical investigation on pain reduction after laparoscopic total or subtotal hysterectomy [22]. The 6388 treatment courses identified by means of the literature search were reported by a total of nine working groups. In three original papers and one meta-analysis the perioperative morbidity after laparoscopic hysterectomy was recorded, three contributions reported surgical complications after laparoscopic, retro- 


\begin{tabular}{|c|c|c|c|c|c|c|c|c|c|c|}
\hline \multirow[t]{2}{*}{ Study cohort } & \multirow[t]{2}{*}{ Cohort size (n) } & \multirow[t]{2}{*}{$\begin{array}{l}\text { Degree of technical } \\
\text { difficulty after Barakat }\end{array}$} & \multirow[b]{2}{*}{$\mathbf{n}$} & \multicolumn{5}{|c|}{$\begin{array}{l}\text { Complications according to } \\
\text { Clavien-Dindo degree of severity ( } n \text { ) }\end{array}$} & \multicolumn{2}{|c|}{$\begin{array}{l}\text { Complications } \\
\text { overall }\end{array}$} \\
\hline & & & & I & II & III & IV & v & (n) & (\%) \\
\hline \multirow[t]{3}{*}{ Our own working group } & 1050 & & & & & & & & 65 & 6.19 \\
\hline & & II & 948 & 26 & 13 & 14 & 0 & 0 & 53 & \\
\hline & & III & 102 & 6 & 5 & 1 & 0 & 0 & 12 & \\
\hline \multirow[t]{5}{*}{ Chi et al. } & 1451 & & & & & & & & 129 & 8.85 \\
\hline & & 1 & 146 & 14 & 1 & 4 & 0 & 3 & 22 & \\
\hline & & $\|$ & 1002 & 42 & 24 & 20 & 0 & 0 & 86 & \\
\hline & & III & 224 & 5 & 5 & 6 & 1 & 0 & 17 & \\
\hline & & IV & 79 & 1 & 1 & 2 & 0 & 0 & 4 & \\
\hline \multirow[t]{2}{*}{ Siedhoff et al. } & 834 & & & & & & & & 130 & 15.59 \\
\hline & & II & 834 & 10 & 78 & 38 & 4 & 0 & & \\
\hline \multirow[t]{2}{*}{ Alperin et al. } & 446 & & & & & & & & 82 & 18.39 \\
\hline & & II & 446 & 30 & 27 & 23 & 2 & 0 & & \\
\hline \multirow[t]{2}{*}{ Fagotti et al. } & 75 & & & & & & & & 3 & 4 \\
\hline & & IV & 75 & 0 & 2 & 1 & 0 & 0 & & \\
\hline \multirow[t]{2}{*}{ Soudaka et al. } & 98 & & & & & & & & 8 & 8.16 \\
\hline & & IV & 98 & 0 & 0 & 7 & 1 & 0 & & \\
\hline \multirow[t]{2}{*}{ Palomba et al. } & 403 & & & & & & & & 166 & 41.21 \\
\hline & & IV & 403 & 44 & 28 & 52 & 40 & 2 & & \\
\hline \multirow[t]{3}{*}{ Kondo et al. } & 2660 & & & & & & & & 264 & 9.92 \\
\hline & & ॥ & 2092 & 100 & 55 & 31 & 0 & 0 & 186 & \\
\hline & & IV & 568 & 38 & 12 & 28 & 0 & 0 & 78 & \\
\hline \multirow[t]{2}{*}{ Gendy et al. } & 332 & & & & & & & & 113 & 34.04 \\
\hline & & II & 332 & 30 & 64 & 19 & 0 & 0 & & \\
\hline \multirow[t]{2}{*}{ Hong et al. } & 89 & & & & & & & & 8 & 8.98 \\
\hline & & IV & 89 & 4 & 2 & 2 & 0 & 0 & & \\
\hline
\end{tabular}

peritoneal lymphadenectomy and in one study each the surgical morbidity after laparoscopic resection of deeply infiltrating endometriosis and after laparoscopic radical hysterectomy with retroperitoneal lymphadenectomy was evaluated. One last publication reported a standardised investigation of the complication rates in oncological patients after laparoscopic gynaecological interventions of various types ( Table 4).

Altogether 146 laparoscopic interventions of difficulty degree I, 5654 interventions of difficulty degree II, 326 interventions of difficulty degree III and 1312 interventions of difficulty degree IV were evaluated.

The registration of the occurring postoperative complications was retrospective in 5360 treatment courses and in the framework of prospective clinical evaluations in 2078 treatment courses.

5220 treatment courses were recorded in investigations in which exclusively patients with a malignant underlying disease were included; 2218 treatment courses were from mixed patient collectives.

2493 of all included treatment courses were from clinical investigations involving cohorts of 500 or fewer patients, 4945 treatment courses were recorded in studies on cohorts of 500 or more patients.

\section{Logistic regression analysis}

In the entire investigated collective, 969 complications occurred (overall complication rate: $13 \%$ ). Of these 664 were mild complications (Clavien-Dindo grade I-II; 8.9\%) and 305 were severe complications (grade III-V; $4.1 \%$ ). The mortality rate in the observed collective amounted to $0.1 \%$ ( Table 4 ).
The binary logistic regression analysis revealed a significant dependence between the covariates degree of technical difficulty, study size, and study centre and the occurrence of surgical complications overall. The covariates data acquisition and study collective did not have a significant influence on the overall rate of observed complications.

After interventions with enhanced and higher degrees of difficulty complications occurred significantly more frequently (rR: 1.37; $\mathrm{p}<0.01$ ). The reason for the increased rate of surgical morbidity was the increased occurrence of severe complications after interventions with enhanced and higher degrees of difficulty (grade III-V; rR: 2.37; p < 0.01). In contrast, for the occurrence of mild complications (grade I-II) there was no significant difference between interventions with enhanced and higher degrees of difficulty and those with low or moderate degrees of difficulty. In clinical investigations of cohorts with 500 and more patients a significantly lower rate of complications was observed compared to those with less than 500 patients (rR: 0.35 ; $p<0.01$ ). This applied not only to the frequency of occurrence of mild complications (rR: $0.33 ; \mathrm{p}<0.01$ ) but also to the occurrence of severe complications (rR: $0.41 ; \mathrm{p}<0.01$ ).

Furthermore in treatment courses from the studies of our own working group a significantly lower rate of complications was observed (rR: $0.19 ; \mathrm{p}<0.01$ ). This lower risk could be observed not only for the occurrence of mild complications ( $\mathrm{rR}: 0.2 ; \mathrm{p}<0.01$ ) but also for the occurrence of severe complications (rR: 0.23 ; $\mathrm{p}<0.01$ ) ( Table 5). 
Table 5 Binary logistic regression analysis, risk factors for the occurrence of complications.

\begin{tabular}{|c|c|c|c|c|c|}
\hline \multirow[t]{2}{*}{ Covariate } & \multirow[t]{2}{*}{ Wald } & \multirow[t]{2}{*}{ Relative risk } & \multirow[t]{2}{*}{$\mathbf{p}$} & \multicolumn{2}{|c|}{ 95\% Confidence interval } \\
\hline & & & & lower value & upper value \\
\hline \multicolumn{6}{|l|}{ Complications overall } \\
\hline Enhanced technical difficulty & 16.32 & 2.04 & $<0.01$ & 1.44 & 2.89 \\
\hline Large study cohort ( $\geq 500$ ) & 59.98 & 0.35 & $<0.01$ & 0.26 & 0.45 \\
\hline Own working group & 34.87 & 0.19 & $<0.01$ & 0.11 & 0.34 \\
\hline Oncological study cohort & 0.84 & 1.18 & 0.36 & 0.82 & 1.69 \\
\hline Retrospective data acquisition & 2.81 & 0.74 & 0.09 & 0.52 & 1.05 \\
\hline \multicolumn{6}{|c|}{ Mild complications (Clavien-Dindo I-II) } \\
\hline Enhanced technical difficulty & 7.45 & 0.75 & 0.06 & 0.62 & 1.02 \\
\hline Large study cohort ( $\geq 500$ ) & 91.41 & 0.41 & $<0.01$ & 0.34 & 0.49 \\
\hline Own working group & 76.51 & 0.23 & $<0.01$ & 0.17 & 0.32 \\
\hline \multicolumn{6}{|c|}{ Severe complications (Clavien-Dindo III-V) } \\
\hline Enhanced technical difficulty & 46.47 & 2.37 & $<0.01$ & 1.85 & 3.03 \\
\hline Large study cohort $(\geq 500)$ & 75.38 & 0.33 & $<0.01$ & 0.26 & 0.42 \\
\hline Own working group & 37.15 & 0.19 & $<0.01$ & 0.11 & 0.32 \\
\hline
\end{tabular}

Enhanced technical difficulty: laparoscopic intervention with degrees of difficulty stages III and IV according to Barakat; large study cohort ( $\geq \mathbf{5 0 0}$ ): analysed treatment courses from study collectives of 500 and more patients; own working group: analysed treatment courses from our own working group; oncological study cohort: analysed treatment courses from oncological study collectives; retrospective data acquisition: retrospective analysis of treatment courses.

\section{Discussion}

Gynaecological-laparoscopic interventions are in general associated with a low surgical morbidity [23-25]. This estimation has been decisively influenced by two investigations on the postoperative morbidity after minimally invasive gynaecological interventions from the last decade of the last century. Chapron and coworkers retrospectively determined the surgical complication rate after gynaecological-laparoscopic operations in seven university endoscopic centres in the period from 1985 to 1995, with inclusion of altogether 29966 patients. The overall complication rate in the investigated collective was given as $0.46 \%$. According to a free-text analysis of the complications listed in the publication there were 96 adverse events that could be assigned to Clavien-Dindo severity stage III and higher. This corresponds to a rate of severe complications of $0.32 \%$ [26]. In a second study in 1997 Harkki-Siren evaluated the data of the Finnish statutory health insurance with regard to claims for reimbursement due to surgical complications after gynaecological-laparoscopic interventions. In the observation period, the statutory insurance funds reimbursed the costs for 70607 gynaecological-laparoscopic operations whereby $0.36 \%$ reimbursement claims due to surgical complications were recorded; in the total of 10 processed claims, the responsible health insurance authorities reported just one case due to a "severe complication". The definition of the term "severe complication" used here essentially corresponds to the severity degree III-V according to Clavien-Dindo [27].

Thereafter appreciably higher complication rates for gynaecological-laparoscopic interventions were reported in prospectively collected monocentric studies. Mirhashemi determined the surgical morbidity rates after gynaecological-laparoscopic interventions in an academic teaching hospital; the overall complication rate in this study amounted to $19.6 \%$ and the rate of severe complications with an indication for surgical revision to $4.7 \%$ [28]. Saidi reported on a similar complication rate (10.4\% overall; $5.1 \%$ severe complications) after gynaecological-laparoscopic interventions of various degrees of difficulty [29]. A French report evaluated 1033 gynaecological-laparoscopic procedures of moderate and enhanced degrees of difficulty (stages III and IV accord- ing to Barakat) at a single treatment centre and stated a complication rate of $3 \%$, the complications mentioned in the publication can be assigned to severity stages III to V according to ClavienDindo [30].

In our own analysis of the data from 10 treatment centres on gynaecological-laparoscopic interventions the determined complication rate was in a comparable order of magnitude with the results of the prospective monocentric studies mentioned above. In comparison with the retrospective evaluations of Chapron and Hakki-Siren, not only the overall complication rate but also the rate of severe complications were, in contrast, about 10 -fold higher. The reason for such a widely different evaluation of the postoperative morbidity risk of gynaecological-laparoscopic operations seems to be inherent to the methodology: Hakki-Siren did not determine the complication rate by evaluation of individual treatment courses but rather from the ratio of reimbursement claims due to surgical complications to the number of all gynaecological-laparoscopic operations reimbursed by the Finnish statutory health insurances in the observation period. The use of such a surrogate parameter for surgical morbidity after operative interventions could represent a bias in the sense of an underestimation of the actually occurring complication rates. In the investigation of Chapron it is not clear which definition of the term "complication" was used in the evaluation of the study collective; a standardised procedure for the registration of the complications occurring in the investigated patient collective was not described in the publication. A free-text analysis of the complications listed by the authors could place them in the severity grades III and higher according to the Clavien-Dindo classification. The occurrence of complications of the severity grades I and II was not reported, this could be indicative of a systematic underestimation in the registration of complications.

On the whole, the differing evaluations of the morbidity of gynaecological-laparoscopic operations by the individual working groups suggests that the use of a laparoscopic approach as such should not a priori be set as being equal to a low complication rate. Instead, it seems that the risks for complications in gynaecological-laparoscopic operations is influenced to an appreciable extent by covariates. 
Among the as yet identified factors responsible for the increased complication risks of gynaecological endoscopy are the degree of technical difficulty of the respective surgical procedure [4], the surgical experience of the operator as well as the question [31] as to whether the respective surgical method is a new or a well established process at the corresponding treatment centre [32, 33]. The influence of accompanying malignant diseases on the surgical morbidity is not evaluated uniformly. Whereas some authors described a significantly higher rate of complications for gynaecological-laparoscopic operations for patient collectives with malignant underlying diseases, other working groups could not detect such a correlation [34,35]. Last but not least, some authors view a retrospective non-standardised registration of the surgical morbidity in the evaluation of surgical treatment procedures as a methodologically intrinsic reason for a systematic underestimation of the actually occurring complication rates [36].

An association of, on the one hand, the degree of technical difficulty of a laparoscopic intervention and, on the other hand, surgical complications was also observed in our studies: interventions with the degrees of difficulty of III and IV according to Barakat exhibit a significantly higher number of severe complications and, in turn, a significantly higher rate of overall morbidity for this intervention group. If we compare the complication rates of gynaecological-laparoscopic treatment procedures with enhanced and higher degrees of difficulty in our own analysis with published data from the last decade of the last century we could get the impression that nowadays such operative interventions paradoxically have a higher rate of morbidity. The averaged complication rate from 10 studies in the years 2004 to 2013 in our own analysis amounts to $18.07 \%$; in contrast Chapron in 1998 reported a complication rate of merely $8.9 \%$ for laparoscopic interventions with an advanced degree of difficulty [26]. A reason for this observed increase of surgical complications in gynaecological-laparoscopic interventions with enhanced and advanced degrees of difficulty could be the ongoing development of endoscopic techniques and the thus associated extension of the field of application of these therapeutic procedures: Chapron used a classification according to Querleu to subdivide the investigated endoscopic treatment procedures according to the respective degree of difficulty [37]. According to Querleu the performance of a laparoscopic hysterectomy is assigned as an intervention of category IV, the highest degree of severity in this classification. More recent classification systems such as the division according to Chi et al. used in our investigations, in contrast, assign laparoscopic hysterectomy as an intervention of the category II (medium degree of difficulty) [10]. On the other hand, surgical techniques, such as laparoscopic retroperitoneal lymphadenectomy, which have expanded the spectrum of endoscopic surgery in gynaecology in the past decades, are considered as interventions of a higher degree of difficulty (category IV). The results of our own investigations suggest that these interventions differ markedly with regard to their postoperative morbidity from the diagnostic and therapeutic interventions of difficulty stages I and II according to Chi.

Previous reports have demonstrated a dependence of the surgical morbidity not only on the surgeon's degree of experience with the respective laparoscopic operation but also on the amount of experience with endoscopic procedures of the entire treating centre $[29,38]$. Here there are differing opinions about the required number of completed surgical interventions in order to ensure the secure mastery of a gynaecological laparoscopic treat- ment. While in some investigations a learning curve of about 30 operations is considered to be sufficient for an experienced surgeon to learn even technically demanding gynaecological-laparoscopic interventions (degree of difficulty IV according to Chi) [19], in a study collective comprising surgeons with different levels of training, other authors have observed an increase in experience as reflected in a decline in the rate of surgical complications even after the performance of 500 laparoscopic interventions [39]. In our own analysis we oriented ourselves on the second estimation of the endoscopic learning curve on the basis of a reference value of 500 performed operations. In such an evaluation there are hints towards a relationship between the experience with laparoscopic methods in the respective treatment centre and the occurrence of surgical complications: in the involved study collectives of more than 500 treatment courses a significantly lower rate of complications was observed. This result can be objectively related to the fact that, in each of the six publications with study collectives of less than 500 patients included in this analysis, experience in the establishment of an up to now new operation technique for the respective study centre was evaluated.

Regarding the question if and to what extent an underlying malignant disease increases the risk for developing complications after gynaecological-laparoscopic interventions, only few studies are available yet: Erekson referred to a case series that analysed predominantly vaginal-operative and gynaecological-surgical interventions performed per laparotomy which revealed a high morbidity risk for patients with an underlying malignant disease [40]. It is not clear to what extent these results may be transferred to gynaecological-laparoscopic procedures. In our own analysis the presence of an underlying malignant disease was not an independent risk factor for the occurrence of surgical complications. Instead, in the numerically largest included cohort of oncological treatment courses, an assessment by a group at Memorial Sloan-Kettering Cancer Center, an even lower complication rate was seen in comparison to the averaged overall morbidity of our investigation ( $9 \%$ compared to $13 \%$ ). The low complication rate of the study cohort at this specialist centre emphasises the significance of an expertise in gynaecological-laparoscopic therapy procedures that is not limited to just technical aspects for the avoidance of surgical complications [10].

In our own analysis, no significant differences were found in complication rates for retrospectively and prospectively evaluated treatment courses. This observation might suggest that the registration of surgical complication rates in retrospective cohort studies could be improved with the help of the Clavien-Dindo system so as to approach the validity of complication rates determined in prospective studies. Beside the terminologically preformulated definition of the term "surgical complication", the conceptual structure of the Clavien-Dindo classification could also be of importance: the division of the degree of severity of a complication is oriented to the respective therapeutic intervention, which would be necessary for the correction of deviations (e.g., antibiosis, operative revision). Since these therapeutic measures are regularly documented in the patient records, such a classification facilitates a valid retrospective registration of complications in surgical case series. 


\section{Conclusions for Clinical Practice}

$\nabla$

With the use of of Clavien-Dindo classification it appears to be possible to limit the methodologically derived underestimation of surgical morbidity in the retrospective evaluation of gynaecological-endoscopic therapeutic procedures. Our own analysis has identified the respective surgical experience of the treating centre as well as the degree of difficulty of the respective intervention to be factors decisively influencing the surgical morbidity of gynaecological-laparoscopic therapeutic procedures.

\section{Acknowledgements}

$\nabla$

The colleagues at the XXIII. Akademische Tagung Deutschsprechender Hochschullehrer in der Gynäkologie und Geburtshilfe of September 2013 are particularly thanked for their numerous constructive suggestions that served to improve this article.

\section{Conflict of Interest}

$\nabla$

None.

\section{References}

1 Veen MR, Lardenoye JW, Kastelein GW et al. Recording and classification of complications in a surgical practice. Eur J Surg 1999; 165: 421-424

2 Sokol DK, Wilson J. What is a surgical complication? World J Surg 2008; 32: 942-944

3 Dindo D, Clavien PA. [Interest in morbidity scores and classification in general surgery]. Cir Esp 2009; 86: 269-271

4 Gruber IV, Schmidt EH, Frank V et al. [Aspects of quality assurance in gynecological endoscopy]. Geburtsh Frauenheilk 2007; 67: 352-358

5 Solomayer EF, Rody A, Wallwiener D et al. Assessment of university gynaecology clinics based on quality reports. Geburtsh Frauenheilk 2013; 73: 705-712

6 Dindo D, Demartines N, Clavien PA. Classification of surgical complications: a new proposal with evaluation in a cohort of 6336 patients and results of a survey. Ann Surg 2004; 240: 205-213

7 Dindo D, Hahnloser D, Clavien PA. Quality assessment in surgery: riding a lame horse. Ann Surg 2010; 251: 766-771

8 Mitropoulos D, Artibani W, Graefen $M$ et al. [Reporting and grading of complications after urologic surgical procedures: an ad hoc EAU guidelines panel assessment and recommendations]. Actas Urol Esp 2013; 37: 1-11

9 Clavien PA, Sanabria JR, Strasberg SM. Proposed classification of complications of surgery with examples of utility in cholecystectomy. Surgery 1992; 111: 518-526

10 Chi DS, Abu-Rustum NR, Barakat RR. Ten-year experience with laparoscopy on a gynecologic oncology service: analysis of risk factors for complications and conversion to laparotomy. Am J Obstet Gynecol 2004; 191: 1138-1145

11 Siedhoff MT, Carey ET, Findley AD et al. Effect of extreme obesity on outcomes in laparoscopic hysterectomy. J Minim Invasive Gynecol 2012; 19: 701-707

12 Alperin M, Kivnick S, Poon KY. Outpatient laparoscopic hysterectomy for large uteri. J Minim Invasive Gynecol 2012; 19: 689-694

13 Fagotti A, Boruta DM 2nd, Scambia G et al. First 100 early endometrial cancer cases treated with laparoendoscopic single-site surgery: a multicentric retrospective study. Am J Obstet Gynecol 2012; 206: 353.e1353.e6

14 Souadka A, Gouy S, Debaere T et al. Laparoscopic para-aortic lymphadenectomy in advanced cervical cancer: morbidity and impact on therapy. Gynecol Obstet Fertil 2012; 40: 153-157

15 Palomba S, Ghezzi F, Falbo A et al. Laparoscopic versus abdominal approach to endometrial cancer: a 10-year retrospective multicenter analysis. Int J Gynecol Cancer 2012; 22: 425-433

16 Kondo W, Bourdel N, Marengo F et al. Is laparoscopic hysterectomy feasible for uteri larger than $1000 \mathrm{~g}$ ? Eur J Obstet Gynecol Reprod Biol 2011; 158: 76-81
17 Kondo W, Bourdel N, Tamburro $S$ et al. Complications after surgery for deeply infiltrating pelvic endometriosis. BJOG 2011; 118: 292-298

18 Gendy R, Walsh CA, Walsh SR et al. Vaginal hysterectomy versus total laparoscopic hysterectomy for benign disease: a metaanalysis of randomized controlled trials. Am J Obstet Gynecol 2011; 204: 388.e1388.e8

19 Hong JH, Choi JS, Lee JH et al. Comparison of survival and adverse events between women with stage IB1 and stage IB2 cervical cancer treated by laparoscopic radical vaginal hysterectomy. Ann Surg Oncol 2012; 19: 605-611

20 Radosa MP, Winzer H, Mothes AR et al. Laparoscopic myomectomy in peri- and post-menopausal women is safe, efficacious and associated with long-term patient satisfaction. Eur J Obstet Gynecol Reprod Biol 2012; 162: 192-196

21 Radosa MP, Diebolder H, Camara $\mathrm{O}$ et al. Laparoscopic lymphocele fenestration in gynaecological cancer patients after retroperitoneal lymph node dissection as a first-line treatment option. BJOG 2013; 120: 628636

22 Radosa JC, Radosa MP, Mavrova R et al. Five minutes of extended assisted ventilation with an open umbilical trocar valve significantly reduces postoperative abdominal and shoulder pain in patients undergoing laparoscopic hysterectomy. Eur J Obstet Gynecol Reprod Biol 2013; 171: 122-127

23 Pini G, Porpiglia F, Micali S et al. Minilaparoscopy, needlescopy and microlaparoscopy: decreasing invasiveness, maintaining the standard laparoscopic approach. Arch Esp Urol 2012; 65: 366-383

24 Brucker S, Rothmund R, Krämer B et al. Cervical detachment using monopolar SupraLoop ${ }^{\mathrm{TM}}$ electrode versus monopolar needle in laparoscopic supracervical hysterectomy (LSH): an interventional, comparative cohort study. Geburtsh Frauenheilk 2013; 73: 1121-1127

25 Juhasz-Böss I, Mallmann P, Möller CP et al. Use of laparoscopy in the treatment of endometrial and cervical cancer - results of a $2012 \mathrm{Ger}$ many-wide survey. Geburtsh Frauenheilk 2013; 73: 911-917

26 Chapron C, Querleu D, Bruhat MA et al. Surgical complications of diagnostic and operative gynaecological laparoscopy: a series of 29,966 cases. Hum Reprod 1998; 13: 867-872

27 Härkki-Sirén P, Kurki T. A nationwide analysis of laparoscopic complications. Obstet Gynecol 1997; 89: 108-112

28 Mirhashemi R, Harlow BL, Ginsburg ES et al. Predicting risk of complications with gynecologic laparoscopic surgery. Obstet Gynecol 1998; 92: 327-331

29 Saidi MH, Vancaillie TG, White AJ et al. Complications of major operative laparoscopy. A review of 452 cases. J Reprod Med 1996; 41: 471-476

30 Leonard F, Lecuru F, Rizk E et al. Perioperative morbidity of gynecological laparoscopy. A prospective monocenter observational study. Acta Obstet Gynecol Scand 2000; 79: 129-134

31 Mac Cordick C, Lécuru F, Rizk E et al. Morbidity in laparoscopic gynecological surgery: results of a prospective single-center study. Surg Endosc 1999; 13: 57-61

32 Chapron C, Pierre F, Querleu D et al. Complications of laparoscopy in gynecology. Gynecol Obstet Fertil 2001; 29: 605-612

33 De Wilde RL. The danger of time-consuming operative laparoscopies: avoiding severe complications. Geburtsh Frauenheilk 2012; 72: 291292

34 Mahdavi A, Peiretti M, Dennis S et al. Comparison of laparoscopic hysterectomy morbidity for gynecologic, oncologic, and benign gynecologic conditions. JSLS 2006; 10: 439-442

35 Canis $M$, Farina $M$, Jardon $K$ et al. Laparoscopy and gynecologic cancer in 2005. J Gynecol Obstet Biol Reprod 2006; 35: 117-135

36 Aaronson DS, Erickson BA, Allareddy V et al. Complications rates of nononcologic urologic procedures in population-based data: a comparison to published series. Int Braz J Urol 2010; 36: 548-556

37 Querleu D, Chapron C. Complications of gynecologic laparoscopic surgery. Curr Opin Obstet Gynecol 1995; 7: 257-261

38 Akin Y, Ates M, Celik O et al. Complications of urologic laparoscopic surgery: a center surgeon's experience involving 601 procedures including the learning curve. Kaohsiung J Med Sci 2013; 29: 275-279

39 Wattiez A, Soriano D, Cohen SB et al. The learning curve of total laparoscopic hysterectomy: comparative analysis of 1647 cases. J Am Assoc Gynecol Laparosc 2002; 9: 339-345

40 Erekson EA, Yip SO, Ciarleglio MM et al. Postoperative complications after gynecologic surgery. Obstet Gynecol 2011; 118: 785-793 